\title{
A influência dos contos de fadas na literatura juvenil brasileira
}

The influence of fairy tales in the brazilian youth literature

\section{Pedro Afonso Barth ${ }^{\mathrm{I}}$}

1 Doutor em Letras pela Universidade Estadual de Maringá (UEM $\backslash 2019)$. Pesquisador no Grupo do CNPq “FORPROLL: Formação de Professores de Línguas e Literatura”. Atualmente, professor colaborador no curso de Letras da Universidade Tecnológica Federal do Paraná (UTFPR) do campus Pato Branco. 
RESUMO: Este artigo analisa obras da literatura juvenil brasileira que se apropriam e ressignificam elementos de contos de fadas. Distinguimos três categorias de análise: a) Obras que apresentam menção e presença intertextual de contos de fadas; b) Narrativas que adaptam e recontam o conto para público juvenil e c) recriação e ressignificação total. Analisamos uma obra juvenil de cada uma das categorias a partir dos conceitos de adaptação e intertextualidade, respectivamente dos estudos de Hutcheon (2011) e Kristeva (1974), além de estudos sobre Contos de fadas e literatura juvenil, a partir de autores como Colomer (2017), Novaes Coelho (2002), Tolkien (2017), entre outros. Concluímos que há na literatura juvenil brasileira uma tendência de revisitar motivos e temas vindos de contos de fadas. Entretanto, temos obras juvenis que apenas ecoam discursividades das narrativas infantis adaptadas a um novo público, e outras que apresentam novos olhares críticos sobre esses conteúdos.

PALAVRAS-CHAVE: Literatura Juvenil; Contos de Fadas; Sagas Fantásticas; Adaptação.

ABSTRACT: This article analyzes books from Brazilian youth literature that appropriate and give a new meaning to elements of fairy tales. We distinguished three categories of analysis: a) Books that present mention and intertextual presence of fairy tales; $b$ ) Narratives that adapt and retell the story for a young audience and c) total recreation and resignification. We analyzed a youth work from each of the categories based on the concepts of adaptation and intertextuality, respectively from the studies of Hutcheon (2011) and Kristeva (1974), in addition to studies on Fairy Tales and youth literature, from authors such as Colomer (2017), Novaes Coelho (2002), Tolkien (2017), among others. We conclude that there is a tendency in Brazilian youth literature to revisit motives and themes from fairy tales. However, we have youth works that only echo discursivities of children's narratives adapted to a new audience, and others that present new critical perspectives on these contents.

KEYWORDS: Youth Literature; Fairy tale; Fantastic sagas; Adaptation. 


\section{Introdução}

Contos de fadas são uma presença marcante e constitutiva da Literatura infantil. Dessa forma, adolescentes de um modo geral, provavelmente, cresceram lendo ou pelo menos conhecendo contos de fadas. Assim, ao lerem histórias juvenis que adaptam ou reelaboram elementos ou personagens de contos de fadas são levados a uma atitude de engajamento em relação a obra lida. Eles irão reconhecer os elementos retratados e recriados de contos de fadas e podem atribuir novos significados a eles. Tal processo pode motivar o que é definido por Linda Hutcheon (2011) como prazer intertextual, ou seja, quando o leitor reconhece marcas conhecidas de outros textos e sente fruição nesse processo. A partir dessa premissa, podemos reconhecer como natural a presença de elementos intertextuais que adaptam, mencionam ou reinterpretam contos de fadas em narrativas para adolescentes e jovens.

O presente trabalho analisará obras juvenis que utilizam referências a contos de fadas em sua composição. O objetivo é classificar e elencar características que vão diferenciar três formas distintas de engajamento intertextual de contos de fadas a partir de obras juvenis. A partir dessa premissa, analisamos três obras da literatura juvenil brasileira contemporânea, cuja textualidade apresenta referências explícitas a contos de fadas. Cinderela Pop, obra de 2015 de autoria de Paula Pimenta, a obra Caçadores de Bruxas de 2007 de Raphael Draccon, obra integrante da saga Dragões de éter e a obra Príncipe Gato e a ampulheta do tempo de Bento de Luca (2014). Essas três obras foram escolhidas porque representam três maneiras de utilização e construção das referências intertextuais aos contos de fadas no tecido discursivo das narrativas juvenis: quando há apenas uma menção, resgate de elementos de um conto de fadas, intertextual, quando o conto de fadas é adaptado e recontado ao público jovem, e finalmente, quando passa por um processo total de recriação e ressignificação.

Como marcos teóricos importantes deste trabalho destacamos os conceitos de adaptação e intertextualidade, respectivamente dos estudos de Hutcheon (2011) e Kristeva (1974), além de estudos sobre Contos de fadas e literatura juvenil, a partir de autores como Colomer (2017), Novaes Coelho (2002), Tolkien (2017), entre outros. 
$\mathrm{O}$ artigo está dividido em quatro seções. A primeira delas aponta a relação entre contos de fadas e literatura juvenil e explicita as três categorias elencadas para análise. Em seguida, temos uma seção em que apresentamos e analisamos a obra Príncipe Gato e a ampulbeta do tempo de Bento Luca, obra esta que apresenta uma menção direta e explícita ao conto $O$ gato de botas. A seção seguinte analisa a obra Cinderela Pop de Paula Pimenta, narrativa que adapta a narrativa infantil de Cinderela ao público juvenil contemporâneo. A terceira seção analisa uma obra que reconfigura e cria completamente contos de fadas, especialmente Chapeuzinho Vermelho. Trata-se de Caçadores de Bruxas de Raphael Draccon.

\section{Contos de Fadas e a Literatura Juvenil}

A relação dos contos de fadas como narrativas de gênese da literatura infantil é amplamente investigada. Tais narrativas, que não eram originalmente direcionadas a leitores específicos, foram adaptadas e remodeladas ao leitor e ouvinte infantil, de tal forma, que é comum muitas pessoas considerarem contos de fadas como sinônimos de literatura infantil. Estudiosos como Colomer (2017), Nelly Novaes Coelho (2012), Bruno Bettelheim (2015), Diana e Mário Corso (2013) são alguns que estudam a importância dessas narrativas para a construção de significações que serão importantes para a infância. Segundo Coelho (2012), os contos de fadas foram repetidamente adaptados por diferentes autores ao longo dos tempos, principalmente em função de uma dupla articulação: por um lado há o interesse lúdico ou dramático do enredo, por outro, há a articulação de uma exemplaridade do comportamento humano evidenciado na narrativa. Exemplaridade que não se confunde com uma mera moral da história, que poderia ser demarcada temporalmente, e sim um valor mais amplo de sabedoria de vida, esta sim com validade para qualquer tempo ou espaço.

Por essa relação e articulação, os contos de fadas são referências muito presentes no mundo ocidental. Por isso, são presentes enquanto elementos de composição de várias narrativas, criadas para as mais variadas faixas etárias, inclusive para os jovens. 
Isso muito se deve à força da fantasia e do maravilhoso como elementos que fascinam e encantam leitores. Na obra Árvore e Folha, Tolkien (2017) publicou o ensaio "Sobre Contos de Fadas", escrito originalmente entre 1938 e 1939. Nesse texto, o autor aponta:

É claro que a Fantasia pode ser levada ao excesso. Pode ser malfeita. Pode ser empregada para maus usos. Pode até mesmo iludir as mentes das quais surgiu. Mas de que coisa humana neste mundo decaído isso não é verdade? Os homens não somente conceberam elfos, mas imaginaram deuses, e os adoraram, adoraram até mesmo aqueles mais deformados pelo mal de seu próprio autor. Mas fizeram falsos deuses a partir de outros materiais: suas opiniões, seus estandartes, seus dinheiros - até suas ciências e suas teorias sociais e econômicas demandaram sacrifício humano. Abusus non tollit usum. A Fantasia continua sendo um direito humano: fazemos em nossa medida e em nosso modo derivativo, porque somos feitos, e não somente feitos, mas feitos à imagem e semelhança de um Criador. (TOLKIEN, 2017, p. 53-54).

$\mathrm{Na}$ citação, o autor defende a fantasia, elemento enraizado nos contos de fadas, apontando inclusive sua importância como um direito humano. Dessa forma, entende-se que os elementos maravilhosos presentes em contos de fadas são coerentes e pertinentes para quaisquer faixas etárias. Como reflexo dessa defesa, podemos citar quase a totalidade da obra literária de Tolkien, especialmente sua obra-prima, O senhor dos anéis, que pode ser considerada um conto de fadas para adultos.

Consequentemente, contos de fadas podem ser endereçados para leitores jovens. Entretanto, é legítimo apontar que Literatura Juvenil apresenta elementos muito específicos (COLOMER, 2017). É uma literatura endereçada para um leitor com uma identidade em construção, um ser movente que vai articular seus interesses e vontades e experimentar sempre o novo. Porém, não é uma página em branco, é um ser que já apresenta leituras de mundo anteriores, ou seja, apresenta uma bagagem anterior de leituras, o que permite o reconhecimento de referências intertextuais. E muitas vezes, irá procurar por elas. Por consequência, obras juvenis com elementos de contos de fadas sempre serão lidas pelo viés dessa referência anterior: considerando que o leitor pode reconhecer as menções intertextuais e estabelecer conexões. 
Sendo assim, espera-se que uma obra juvenil leve o seu leitor à ressignificações, que amplie o seu horizonte de expectativa e não traga apenas meras reproduções ou recontos de contos de fadas. Na leitura de obras juvenis brasileiras observamos os mais diversos usos de tais referências intertextuais. Destacamos três delas: a) menção e presença intertextual de contos de fadas na obra juvenil b) adaptação e reconto de um conto de fadas adaptado ao público juvenil e c) recriação e ressignificação de um conto de fadas.

Para compreender a primeira das formas, vamos retomar o conceito de intertextualidade. O uso do termo foi iniciado pela estudiosa Julia Kristeva (1974) a partir de leituras de Bakhtin. A autora aponta que todo texto se constrói como um mosaico das mais variadas citações, explícitas ou implícitas, já que pode absorver e transformar uma multiplicidade de elementos vindos de outros textos. Assim, de maneira genérica, a intertextualidade faz com que o texto literário não seja fechado em si mesmo, e sim que dialogue e tenha pontos em contato com outras obras. Entretanto, chamamos atenção para obras que têm a intertextualidade como elemento intrinsecamente constitutivo, ou seja, sem compreender as relações e releituras de outros textos, não é possível fazer uma leitura global. Assim, paira nessas obras juvenis a menção a um conto de fadas. Quando o leitor for capaz de relacionar a menção ao seu intertexto, há a possibilidade de uma leitura mais ampla da narrativa em questão.

Em relação à segunda modalidade apresentada neste estudo, adaptação e reconto de um conto de fadas adaptado ao público juvenil, é produtivo retomar o conceito de adaptação. Linda Hutcheon aponta que "a adaptação, do ponto de vista do adaptador é um ato de apropriação ou recuperação, e isso sempre envolve um processo duplo de interpretação e de criação de algo novo." (HUTCHEON, 2011, p. 45). Dessa forma, a adaptação é uma forma de repetição, porém é uma repetição que não implica um uma simples replicação, já que tem potencial de alterar elementos. Na perspectiva de Hutcheon, antes de ser criador, o adaptador é um intérprete e além disso, a transposição criativa da história de uma obra adaptada está sujeita ao temperamento e talento do adaptador.

Um elemento que justifica o interesse do leitor na leitura de uma história adap- 
tada de outra fonte é o aspecto relacionado ao prazer intertextual na adaptação, já que segundo Hutcheon (2011, p, 46) "tal como a imitação clássica, a adaptação estimula o prazer intelectual e estético de compreender a interação entre as obras, de abrir os possíveis significados de um texto ao diálogo intertextual.” Assim, para muitos, ver uma nova versão de uma história já conhecida é uma experiência não só válida, como almejada, já que permite essa abertura a outras percepções e releituras.

Para compreensão da terceira forma analisada - recriação e ressignificação de um conto de fadas- os dois conceitos citados são importantes, intertextualidade e adaptação. Mas com uma diferença significativa: há a abertura para a recriação e reestruração, não apenas replicação da narrativa conhecida. Para tanto, é muito importante resgatar o princípio de Hutcheon (2011) sobre adaptações: a indicação de que a fidelidade não deve ser um critério de análise para atestar a qualidade de uma história adaptada. Na perspectiva da autora, o que deve guiar a análise de uma adaptação são três perspectivas distintas. Primeiro perceber que o texto produzido é uma adaptação por parecer ser a transposição declarada de uma ou até mais de uma obra reconhecível. Em segundo lugar, é preciso reconhecer na obra adaptada o processo de criação, ou seja, a percepção do ato criativo e interpretativo de apropriação e de recuperação de uma história. O terceiro fato é a percepção do engajamento intertextual com a obra adaptada, ou seja, a percepção que uma "adaptação é uma derivação que não é derivativa, uma segunda obra que não é secundária - ela é a sua própria coisa palimpséstica.” (HUTCHEON, 2011, p. 30).

\section{Menção e presença intertextual de contos de fadas em uma obra juvenil}

A primeira categoria que analisaremos é a que trata de uma menção ou presença intertextual de contos de fadas em uma obra juvenil. Nesse caso, há um referente intertextual que serve como ponto de partida para ler a nova narrativa. Porém, a história original não é adaptada e nem recriada. Apenas é mencionada. 
Como um exemplo, citamos a obra $O$ príncipe Gato e ampulbeta do tempo do autor Bento de Luca, que na verdade é um pseudônimo de dois autores, Marcelo Siqueira e Gustavo Almeida. A história, publicada em 2014, narra a história de um gato guerreiro, príncipe de um universo chamado Marshmallow. Ele precisa viajar entre mundos e chega até a cidade brasileira de São Paulo, em busca de um artefato: uma ampulheta do tempo que pode salvar o seu mundo da destruição. Nessa odisseia, ele encontra o jovem Hugo, um humano comum que se vê enredado na aventura e passa a ajudar o gato falante, mesmo odiando a personalidade do bichano. A narrativa, na realidade, compreende uma trilogia, com uma história mais ampla e intrincada, que inclusive pode ser lida enquanto saga fantástica - conceito do autor espanhol Martos Garcia (2009). Saga fantástica, a partir de Martos Garcia (2009) é uma modalidade transmidiática das narrativas modernas, uma história com elementos insólitos que permite uma ampla expansão de seu mundo - paracosmos. Uma saga fantástica assim será composta por um ou mais volumes, construirá um mundo ficcional próprio, com histórias e geografias únicas e terá uma porosidade para adaptações, sequências e até mesmo prequelas. Príncipe Gato pode ser lida como saga fantástica por apresentar tais características: temos um mundo - Marshmallow, com uma história, geografia e características.

A saga do Príncipe gato pode ser considerada como juvenil por diversos fatores como pelo perfil dos personagens principais, os conflitos identitários dos protagonistas, o projeto gráfico e editorial da trilogia, entre outros aspectos.

Temos na narrativa a presença de um elemento intertextual que pode remeter à menção a um personagem clássico dos contos maravilhosos ou de fadas ${ }^{2}$. Trata-se do Gato de Botas. O Príncipe Gato é um membro da realeza de um mundo habitado por animais falantes. Ele é nobre, atrevido, impulsivo e ao longo da narrativa vai interagir muito com um humano, a quem gradativamente terá afeição e consideração. A personalidade do personagem, a forma com que ele interage com o humano e a

2 Na perspectiva deste trabalho não faremos distinção entre contos maravilhosos e contos de fadas. Para saber mais sobre suas diferenças e possibilidades de análise, consultar Coelho (2012). 
maneira que anda e se comunica são elementos que sugerem, mencionam e retomam o Gato de botas ou Mestre Gato, personagem de conto de fadas recriado por Charles Perrault. Ambos os gatos se envolvem em movimentos que podem ser relacionados à Jornada do Herói de Campbell (2007)³ e também há a presença de uma das premissas basilares dos contos de fadas, já que segundo Coelho, “a efabulação básica do conto de fadas expressa os obstáculos ou provas que precisam ser vencidas, como um verdadeiro ritual iniciático, para que o herói alcance suas auto-realização existencial [...]" (COELHO, 2012, p. 13).

O leitor que possuir a referência do conto original consegue criar um relação intertextual, pois na narrativa, um gato ladino e astuto consegue fazer com que seu amo e senhor, originalmente pobre, fique rico e bem sucedido, casando ao final da história com uma linda princesa. Em O Príncipe Gato há uma inversão: é justamente o humano falho e não tão astuto que conduz um gato esperto a um caminho de autodescobertas. Não é um caminho de simples ganhos e casamento e sim uma jornada de enfrentamento de inimigos e superação de obstáculos, em que o final feliz é a salvação de um universo inteiro.

O personagem Príncipe Gato inicia a narrativa com uma postura arrogante e autossuficiente e ao longo da narrativa vai se humanizado e passa a considera o humano como amigo. Dessa forma, o relacionamento do Príncipe Gato com Hugo, o humano, apresenta uma evolução, de uma antipatia mútua, evoluindo para uma sólida

3 Jornada do herói é um conceito desenvolvido por Joseph Campbell (2007). Segundo o autor, todas as narrativas da humanidade, de povos de culturas distintos, teriam a tendência a reproduzir o mesmo movimento narrativo: a Jornada de um personagem que empreende uma busca salvadora e assim torna-se um herói. Assim, todas as histórias teriam os mesmos passos ou elementos com a possibilidade de algumas omissões: "Caso um ou outro dos elementos básicos do padrão arquetípico seja omitido de um conto de fadas, um ritual, uma lenda ou um mito particular, é provável que esteja, de uma ou de outra maneira, implícito -e a própria omissão pode dizer muito sobre a história e a patologia do exemplo" (CAMPBELL, 2007, p. 42). 
amizade. Assim, não é possível caracterizar uma relação de mestre e vassalo, amo e criado verificada no texto original.

De qualquer forma, há uma clara menção intertextual. Retomando o conceito de intertextualidade de Kristeva, a autora afirma que "para os textos poéticos da modernidade, poderíamos afirmar, sem risco de exagero, é uma lei fundamental: eles se constroem absorvendo e destruindo, concomitantemente, outros textos do espaço intertextual" (KRISTEVA, 1974, p. 96). Assim, a intertextualidade é constitutiva, mesmo quando o leitor não a percebe. Além disso é preciso levar em que há uma duplicidade pois, "o texto poético é produzido no movimento complexo de uma afirmação e de uma negação simultânea de um ou outro texto" (KRISTEVA, 1974, p. 96). Dessa forma, entre O príncipe gato e o Gato de botas há uma intertextualidade explícita, que tanto afirma uma proximidade entre os personagens, quando marca as diferenças que acontecem ao longo da narrativa.

Portanto, não podemos considerar O Príncipe Gato como uma adaptação da história e nem como uma recriação do Gato de Botas, já que os personagens não se confundem. A personagem Príncipe Gato não é o Gato de Botas. É possível indicar uma relação implícita entre as obras, mas é possível ler a trilogia de Bento de Luca sem conhecer ou considerar o conto de Perrault. Em suma, conhecer o Gato de Botas permite que a leitura de $O$ Príncipe Gato e a ampulbeta do tempo seja mais ampla, mas não é uma condição para compreensão de leitura, pois as duas obras não revivem a mesma narrativa.

Outra diferença importante é que na obra de Bento de Luca, o Príncipe Gato passará por uma série de conflitos, tarefas e desafios que tornam o personagem mais complexo. Já no Gato de Botas, a narrativa culmina na construção de uma moral que coloca o humano em primazia e o animal falante em segundo plano. Como podemos observar nos versos finais do conto: "Se um filho de um moleiro, com presteza, / Cativa o coração de uma princesa, / E atrai o seu olhar enamorado, / É que para inspirar tal ternura / Aparência, juventude e formosura / São recursos a ser considerados” (PERRAULT, 1994, p. 70).

Assim, concluímos que na obra $O$ príncipe Gato e ampulbeta do tempo, a história 
original não é adaptada e nem apresenta novas significações relacionadas aos contos de fadas. $\mathrm{Na}$ realidade, o conto de fadas é usado apenas como chamariz, como uma espécie de muleta narrativa, que possibilita reflexões acerca da evolução das personagens. Assim, como no exemplo citado, outras obras juvenis podem exercer o mesmo engajamento intertextual.

\section{Adaptação e reconto de um conto de fadas adaptado ao público juvenil}

A segunda categoria que analisaremos será a relação de adaptação entre um conto de fadas, culturalmente construído como uma narrativa infantil, para uma obra para adolescentes e jovens. Como exemplo dessa articulação, apresentamos a obra Cinderela Pop, da autora brasileira Paula Pimenta, e sua relação com o conto Gata Borralheira, conhecido como Cinderela.

Hodiernamente, a autora Paula Pimenta vem sendo uma presença constante nas listas de obras mais vendidas para crianças e jovens no Brasil. Ela é representante de um filão: obras protagonizadas por garotas adolescentes que vivem conflitos normais para a faixa etária: amores não correspondidos, namorados, bullying, popularidade, construção identitária, conflitos com pais e a indefinição em relação aos planos para o futuro. Um dos seus projetos literários é o desenvolvimento de uma sequência de livros que apresenta a seguinte premissa: adaptação de histórias de personagens clássicas, frequentemente princesas, para os tempos contemporâneos. Em suma, é operado um processo adaptativo em personagens dos contos de fadas para adolescentes brasileiras do século XXI. Uma das obras desse projeto é Cinderela Pop, uma atualização do conto Cinderela.

Cintia é a Cinderela do século XXI. Uma adolescente antenada e sonhadora, que cultiva a secreta profissão de DJ. Vive com a tia, pois a mãe mora em outro país. Porém, vive perto do pai e a madrasta, que são presenças marcantes em sua vida. Com eles tem uma relação cheia de proibições e provações, por isso, esconde de todos, 
menos da tia e da mãe, sua profissão de DJ. Seu desespero com a situação chega ao máximo em determinada noite em que acontecerá uma balada imperdível, em que ela precisa trabalhar como DJ. Porém, descobre que tal festa é o aniversário de quinze anos das filhas de sua madrasta, ocasião que seu pai quer que ela se vista como uma princesa e que obrigatoriamente compareça. Assim, com a ajuda de uma amiga e sua tia, Cintia monta dois figurinos. O primeiro é com um look com máscara, uma rainha pop descolada, que usa um All star. O segundo é uma roupa suntuosa de princesa debutante. Assim, ela tocará como DJ até meia noite e depois troca de roupa para o pai e a madrasta não suspeitarem de nada.

O restante dos acontecimentos da trama é compatível com a conhecida narrativa de Cinderela: no agito noturno, a garota conhece o garoto perfeito (ao invés de um príncipe ele é um cantor pop do momento), eles conversam e desenvolvem uma conexão especial. Porém, ela precisa sair antes da meia noite para não despertar a ira do pai e da madrasta. Na fuga, perde o seu All Star. O garoto então usa suas redes sociais para engajar seguidores e assim conseguir localizar a sua garota especial, a sua própria Cinderela particular Porém, a madrasta descobre a fuga e tenta fazer com que seja uma de suas filhas a sortuda escolhida de Fredy Prince, o artista do momento. No ápice da trama, Cintia precisa morar com o pai e a madrasta e é impedida de revelar-se a DJ Cinderela que encantou Fredy Prince, pois por um estratagema de sua madrasta, seu pai a proíbe de ir em uma festa de formatura, festa de o cantor espera que sua amada se revele. Nesse ponto, é ajudada por uma fada madrinha: sua mãe que vem de avião do Japão salvá-la da prisão forçada e recupera um lindo vestido que possibilita que Cintia possa ir ao baile e assim encontrar seu amado. Em suma, a narrativa é absolutamente relacionável com a narrativa original de Cinderela, porém ela é vivida por uma adolescente e com forte presença de elementos do mundo atual dos jovens, como redes sociais, música, blogs, entre outros.

Com a descrição do enredo, torna-se óbvio o processo adaptativo empreendido da narrativa de Paula Pimenta em relação à Cinderela. Este é um conto particularmente conhecido, tanto por ser contado por Charles Perrault e pelos Irmãos Grimm, como adaptado para muitos filmes e desenhos animados. Em Cinderela Pop temos um diálogo 
direto com todos esses textos anteriores, pois a narrativa é adaptada: todos os elementos são "modernizados", configurados em uma nova roupagem, mas a narrativa permanece a mesma. Assim, Cintia é Cinderela, uma nova versão da personagem clássica, mas é ela, uma encarnação de uma figura conhecida. Alguns pontos não coincidem, porém, conforme os pressupostos da teoria da adaptação de Hutcheon (2011), a fidelidade não deve ser o elemento que conduz a leitura e análise de uma adaptação, já que ela é um produto novo, resultado de um exercício de reinterpretação do adaptador. Como citamos anteriormente, a transposição criativa da história de uma obra adaptada está sujeita ao temperamento e talento do adaptador e verificamos isso em Cinderela Pop, que adapta a narrativa de Cinderela ao formato das Chick-lits ${ }^{4}$ contemporâneas. Assim, Cintia tem celular, está inserida em mundo imerso em redes sociais e contatos, vai à escola, precisa resolver problemas comuns a qualquer adolescente, e é nesse contexto que encontra o seu "príncipe".

Coelho (2000, p.178) aponta que “destino, determinismo, fado são presenças constantes nas histórias maravilhosas, onde tudo parece determinado a acontecer, como uma fatalidade a que ninguém pode escapar”, essa relação inescapável acompanha Cintia: ela é destinada a conhecer Fredy Prince, a se apaixonar, a enfrentar a madrasta. A diferença está nos elementos encadeadores do conflito. Se o conto de fadas mobiliza o maravilhoso, fada madrinha, magia, trapos que viram um majestoso vestido, sapatinhos de cristal e outros recursos, a história contemporânea abre mão do insólito e investe em soluções verossímeis com os tempos que correm: redes sociais, engajamento, mídias, personalidades midiáticas, All Star, entre outros.

Em relação a um desses elementos, a fada madrinha, podemos relacioná-la com o seguinte conceito:

4 Tomé e Bastos (2011) definem Chick-Lit como uma modalidade de narrativa juvenil atual: histórias centralizadas em protagonistas femininas que vivem conflitos que são resolvidos a partir de um mergulho em sua feminilidade. Uma recorrência é a busca do amor perfeito, da vivência de uma relação romântica que supra as necessidades da personagem principal; 
A fada é a personagem que encarna a possível realização dos sonhos ou ideais inerentes à condição humana. A missão das fadas nas histórias infantis é prever e prover o futuro de algum. Limitado pela materialidade de seu corpo e do mundo em que vive, é natural que o homem tenha desejado sempre uma ajuda mágica. Entre ele e a possível realização se seus sonhos, aspirações, fantasia, imaginação... sempre existiram mediadores (fadas, talismãs, varinhas mágicas...) e opositores (gigantes, bruxas ou bruxos, feiticeiros, seres maléficos...). (COELHO, 2000, p.174).

A citação acima descreve exatamente a função da fada: ela é um elemento de esperança, uma solução mágica que resolve problemas que no mundo natural seriam intransponíveis. A fada provê o futuro de um personagem, é o mediador do sonho e isso é confrontado por um opositor, que frequentemente também lança mão de poderes ou de forças mágicas. Em Cinderela Pop, a função de esperança é recuperada pela mãe, que de longe, do Japão, fala com a filha por aplicativos de celular, e no ápice da história vem de avião resgatar a filha da "prisão", possibilitando a fuga da filha. Além disso, durante o baile projeta com ajuda da tia de Cintia, um vídeo que esclarece todos os desencontros entre a DJ Cinderela e Fredy Prince. Assim, soluções maravilhosas são substituídas por soluções tecnológicas, porém continuam sendo intermediadas por uma personagem salvadora.

Em relação à ambientação de contos de fadas, é importante considerar o tempo e o espaço. Em relação a isso, é pertinente pontuar que:

[...] o conto de fadas não especifica nem época nem local em que se passa a história. Esta indeterminação não significa, no entanto, que a história, em princípio, se passa em qualquer época, mas sim num passado muito longínquo. A representação estilizada da realidade constitui o mundo do conto de fadas sem sujeitá-lo às leis naturais, integrando-lhe o elemento sobrenatural e garantindo que este seja aceito com naturalidade pelo leitor/ouvinte. (VOLOBUEF, 1993, p. 103).

A não especificação de tempo e espaço de um conto de fadas é uma das garantias de verossimilhança da história. $\mathrm{Na}$ adaptação contemporânea esse aspecto também 
é adaptado. Aqui há uma definição espacial e temporal mais redutora: apesar de não haver indicação de cidade, fica claro que é uma grande cidade brasileira, durante os anos 2000 .

Assim, observamos em Cinderela Pop um bem sucedido processo adaptativo, coerente com o público alvo pretendido. Cintia é a mesma Cinderela do conto original, mas em um outro tempo, outro espaço e age conforme esse novo contexto: é uma adolescente contemporânea. E seguindo a mesma lógica, o maravilhoso é adaptado a essa nova situação, sendo omitido e transmutado em soluções tecnológicas.

Entretanto, é importante ressaltar que apesar de ser um processo adaptativo muito bem sucedido, há algumas questões que podem ser problematizadas. No artigo "Entre cinderelas e belas adormecidas: representações femininas na literatura juvenil contemporânea" (BARTH, 2018), empreendemos uma análise das representações femininas que ecoam em Cinderela Pop e concluímos que é uma narrativa que segue fielmente os sentidos do conto original, ou seja, reproduz discursos patriarcais que poderiam parecer datados. Por exemplo, Cintia é uma personagem que passa a se definir pelo encanto e pela paixão ao seu príncipe. Sua construção como personagem é completamente guiada para viver um relacionamento amoroso, assim como a da Cinderela Original era ser conduzida ao casamento com o príncipe encantado. O sentido de felizes para sempre para as mulheres é o mesmo: a felicidade é somente possível pelo relacionamento com um homem perfeito. Assim, a narrativa pode ser relacionada com um grupo de "histórias que refletem o discurso da fragilidade feminina e escondem a necessidade de as mulheres começarem a articular seus próprios valores e opiniões" (RIBEIRO, 2006, p. 74).

Entretanto, analisar criticamente a manutenção da mesma discursividade não significa condenar a leitura da obra. Pelo contrário, este deve ser um incentivo para questionamentos, para refletir sobre as limitações dos discursos apresentados. Até porque a narrativa, além de ser um dos livros mais vendidos da autora, apresenta um apelo entre leitores. Um exemplo disso é que no ano de 2019 a obra recebeu uma adaptação para o cinema e Cintia foi interpretada por Maísa Silva, grande estrela juvenil desta década. Compreender o engajamento intertextual de uma adaptação com sua obra 
original permite problematizar também como discursos e representações que deveriam estar superados ainda são presentes e reiterados. Assim, abre espaço para refletir sobre qual a sociedade que vivemos e como estão sendo formadas as próximas gerações.

Cinderela Pop, conforme exposto, é um exemplo de uma adaptação que atua como reconto da história original, adaptada a um novo público, o adolescente do século XXI. Assim, como na obra citada, há outras que estabelecem a mesma relação intertextual adaptativa. A partir dessa identificação é possível perceber como a adaptação foi realizada e quais elementos foram transformados ou se houve apenas uma reincidência de discursos.

\section{Recriação e ressignificação de um conto de fadas}

Nesta seção, apresentamos um exemplo de recriação e ressignificação de um conto de fadas. Trata-se da obra Caçadores de Bruxas escrita por Raphael Draccon. Ela foi publicada originalmente em 2007 e faz parte de uma saga intitulada Dragões de Éter.

Atualmente é uma trilogia composta, além da obra citada, por Corações de Neve e Círculos de Chuva. Porém, ampliações ainda podem ser publicadas, já que a história pode ser analisada enquanto uma saga fantástica (MARTOS GARCIA, 2009) ou seja, é uma história que cria um mundo e assim apresenta possibilidades múltiplas de ampliação. O universo paralelo da trama é chamado de Nova éter. Trata-se de um mundo repleto de novos reinos, novas nações, novas culturas, novas raças, novos povos. Uma característica marcante desse novo mundo é que seus personagens são reelaborações de contos de fadas. Assim, temos novas versões de personagens como Capitão Gancho, Branca de Neve, Príncipe Sapo, João e Maria, entre outros. Dessa galeria, destacamos uma personagem específica, a versão de Nova Éter de Chapeuzinho Vermelho.

Chama-se Ariane, e ela é conhecida pelos habitantes de sua região como Chapeuzinho Vermelho. Os leitores descobrem que na realidade a capa que a personagem usava era branca - pois a menina seria iniciada em magia branca. Entretanto, ela passa a ser conhecida como menina da capa vermelha, porque sua roupa inteira foi 
manchada com o sangue da sua avó, durante o ataque mortal de um lobo maligno e possuído. O lobo era um animal encantado com magia negra por uma bruxa maligna e sua missão era matar Ariane por ela ser uma bruxa boa que iria ser iniciada pela grande sacerdotisa, a sua avó.

Chapeuzinho Vermelho é uma das narrativas de contos de fadas mais analisadas por psicólogos, psicanalistas e estudiosos da literatura infantil. Os sentidos e relações da personagem, sua capa vermelha, seus diálogos com o lobo permitem muitas interpretações. Uma delas é a menção ao início da vida sexual de uma jovem mulher e dos riscos de perder a virgindade. Outra é a moral explícita dos perigos de crianças falarem com estranhos. Esses sentidos e moralidades são completamente ressignificados e modificados na versão de Nova Éter.

Para compreender a recriação de Chapeuzinho Vermelho é preciso levar em conta que ela é apenas uma engrenagem de uma trama maior, a história dos Caçadores de Bruxas. No principal reino em que a história se passa, as bruxas são consideradas seres malignos e por isso são caçadas e queimadas vivas, para extirpar a ameaça que representam. A presença de bruxas boas representa um conflito, pois elas precisam provar que não são uma ameaça para a população e assim precisam enfrentar preconceito e intolerância, já que há o impulso de condená-las à fogueira pelo simples fato de serem bruxas.

No decorrer da história, Ariane vai descobrindo sua origem mágica e resolve assumir sua condição. Ao se assumir, ela precisa entrar em confronto duplo: com a sociedade que não reconhece bruxas boas e tentará matá-la e com as bruxas malignas de outro clã, responsáveis pela morte de sua avó.

Em relação a recriação da trama de Chapeuzinho Vermelho, destacamos o seguinte trecho, retirado do epílogo da obra:

Por que a avó de Chapeuzinho Vermelho morava sozinha no meio de uma floresta? E qual diabos é o nome dessa garota? E por que ela foi enviada sozinha pela mãe? Se eu tentasse ir sozinho para a escola com aquela idade, minha avó me daria uns cascudos (se soubesse que lobos estivessem por aí, então...). (DRACCON, 2010, p. 426). 
No trecho, o autor enuncia alguns questionamentos que de certa forma ajudam a entender o processo criativo que culminou na criação dessa versão da Chapeuzinho Vermelho. Podemos perceber que a história surgiu completamente relacionada com a narrativa original, pois ela é fruto das lacunas e espaços em branco que foram, de certa forma, preenchidos por um leitor-criador. Ou seja, temos aqui uma recriação total da história.

Assim, Ariane é a Chapeuzinho Vermelho, mas uma nova versão da personagem, recriada a partir da lógica desse mundo ficcional novo, Nova Éter. Consequentemente, ela obedece a uma nova lógica e toda sua trajetória é ressignificada. Importante citar que também podemos considerar a recriação como um processo adaptativo, relacionando com os pressupostos da teoria de adaptação de Hutcheon (2011). Dessa forma, não temos a replicação da narrativa conhecida, mas sua reformulação, sua recriação.

Um ponto que desperta a atenção é a função que o insólito apresenta na narrativa. Na trama original, o maravilhoso é manifestado no comportamento do lobo, que fala e age como um ser humano. Na versão de Draccon, o insólito é ampliado, pois a própria Chapeuzinho Vermelho tem poderes e magia. Nessa perspectiva, torna-se produtivo resgatar a definição de contos de fadas de Corso e Corso (2006):

Contos de fadas não precisam ter fadas, mas devem conter algum elemento extraordinário, surpreendente, encantador, por isso os contos são maravilhosos. Maravilhoso provém do latim mirabilis, que significa admirável, espantoso e extraordinário. (CORSO; CORSO, 2013, p.27).

Não há fadas na trama original: há apenas a presença do maravilhoso. Se considerarmos uma bruxa boa como uma espécie de fada, podemos apontar que uma mudança recriadora em Caçadores de bruxas, é a introdução de fadas em Chapeuzinho Vermelho. Com essa e outras mudanças, a jornada da personagem é ampliada e todos os signos admitem outras interpretações. Importante apontar que essas mudanças acompanham os interesses do público alvo, pois as questões de identidade, como a de assumir sua identidade como bruxa, podem ser metáforas poderosas para diferentes mudanças que ocorrem durante o período da adolescência. Além disso, a nova versão 
de Chapeuzinho Vermelho mobiliza outros intertextos que provocam o engajamento e identificação do leitor jovem. Dessa forma, o leitor juvenil é posto diante de um desafio: compreender as novas motivações de personagens que pareciam ser conhecidos.

Assim, exemplificamos uma terceira possível forma de engajamento intertextual de obras juvenis com contos de fadas. Como no exemplo citado, outras obras juvenis empreendem o mesmo movimento de recriação total de histórias, personagens e motivações.

\section{Considerações Finais}

O presente artigo teve como objetivo analisar obras da literatura juvenil brasileira que apresentassem a articulação de elementos intertextuais de contos de fadas, criando três categorias de análise, cada uma delas exemplificando uma forma distinta de engajamento intertextual.

As três categorias são: a) Obras que apresentam menção e presença intertextual de contos de fadas; b) Narrativas que adaptam e recontam o conto para público juvenil e c) recriação e ressignificação total. O primeiro caso apresenta uma menção a um personagem de contos de fadas, mas não é ele propriamente, apenas alguns aspectos intertextuais são recuperáveis. Assim, no exemplo citado temos a menção a um gato falante e inteligente, o que nos remete à imagem do Gato de Botas. A segunda categoria diz respeito a narrativas que adaptam completamente a trama, anteriormente considerada infantil, para um novo público. No exemplo analisado, Cintia é uma Cinderela, Pop e contemporânea, que atualiza a personagem Cinderela do conto original. Entretanto, é uma atualização superficial, já que a Cinderela adolescente reproduz os mesmos comportamentos e atitudes da Cinderela original, e assim, o que é realmente atualizado são os elementos de composição da narrativa. Assim, a história de Paula Pimenta é criada em um tempo e espaço determinado e substitui elementos insólitos por tecnológicos e por situações verossímeis com o contexto do século XXI. A terceira categoria representa uma recriação total de personagens ou tramas conhecidas dos 
contos de fadas. Como no exemplo apresentado, temos a presença da Chapeuzinho Vermelho, mas a personagem é recriada em um novo mundo, com outras motivações e ambientações.

Destacamos que os mecanismos de engajamento intertextual de obras juvenis com contos de fadas não foram esgotados neste artigo. Outras relações são possíveis e podem ser descritas. Além disso, o fundamental não é o mero fato de classificar narrativas juvenis em categorias. A principal contribuição do presente estudo é a possibilidade de criar um aparato para refletir sobre os intertextos presentes em narrativas juvenis e como tais elementos podem criar histórias com qualidade literária ou não.

Em suma, este artigo contribui na formatação de um aparato crítico que pode auxiliar na análise de referências a contos de fadas em obras da literatura juvenil. Dessa forma, conclui-se que as formas de engajamento intertextual com contos de fadas são distintas. Assim, teremos obras juvenis que apenas ecoam discursividades das narrativas infantis adaptadas a um novo público, enquanto outras irão reelaborar novos olhares críticos sobre esses conteúdos. 


\section{Referências}

BARTH, Pedro Afonso. Entre cinderelas e belas adormecidas: representações femininas na literatura juvenil contemporânea. Entremeios [Revista de Estudos do Discurso, Universidade do Vale do Sapucaí (UNIVÁS), Pouso Alegre (MG), vol. 17, p. 289-299, jul. - dez. 2018.

BETTELHEIM, Bruno. A psicanálise dos contos de fadas. São Paulo: Editora Paz e Terra, 2015.

CAMPBELL, Joseph. O Herói de Mil Faces. São Paulo, SP: Cultrix/Pensamento, 2007.

COLOMER, Teresa. Introdução à literatura infantil e juvenil atual. Tradução de Laura Sandroni. São Paulo: Global, 2017.

CORSO, Diana Lichtenstein; CORSO, Mário. Fadas no divã: psicanálise nas histórias infantis. Artmed Editora, 2013.

COELHO, Nelly Novaes. O conto de fadas: Símbolos, mitos, arquétipos. São Paulo: Editora Paulinas, 2012.

DRACCON, Raphael. Dragões de Éter: Caçadores de Bruxas. São Paulo: Leya, 2010.

LUCA, Bento. O príncipe gato e a ampulheta do tempo. São Paulo: Novo Século Editora, 2013.

MARTOS GARCIA, Alberto. Introducción al mundo de las sagas. Badajoz: Universidade de Extremadura, 2009. 
PERRAULT, Charles. Mestre gato ou o gato de botas. In: Contos da mamãe gansa. Tradução Elisa Tamajusuku, Maria Alves Müller e Maria Stella Dischinger da Cunha. Porto Alegre: Paraula, 1994. p. 53-70.

PIMENTA, Paula. Cinderela Pop. Rio de Janeiro: Galera Record, 2015.

RIBEIRO, Eliane. Fragilidade e força: personagens femininas em Charles Perrault e no mito da donzela Guerreira. Brasília: Éclat, 2006.

TOLKIEN, John Ronald Reuel. Sobre bistórias de fadas. Tradução: Ronald Kyrmse. São Paulo: Conrad Editora do Brasil, 2017.

TOMÉ, Maria da Conceição; BASTOS, Glória - A herança dos irmãos Grimm na literatura juvenil contemporânea : a "chick-lit" e as princesas do novo milénio. "Agália [Em linha] : revista de estudos na cultura”. n. 103 (2011), p. 7-29. Disponível em: https://repositorioaberto.uab.pt/bitstream/10400.2/3216/1/artigoagalia.pdf Acesso em: 20 abr. 2020.

VOLOBUEF, K. Um estudo do conto de fadas. Revista Letras, Araraquara: Editora UNESP, 1993, p. 99-114. 